\title{
ПРОГРАММНО-МЕТОДИЧЕСКОЕ ОБЕСПЕЧЕНИЕ ГРУПП НАЧАЛЬНОЙ ПОДГОТОВКИ СПОРТСМЕНОВ В ДИСЦИПЛИНЕ СПОРТИВНОГО ТУРИЗМА «ДИСТАНЦИЯ-ПЕШЕХОДНАЯ»
}

\section{THE SOFTWARE AND METHODOLOGICAL SUPPORT FOR THE GROUPS OF INITIAL TRAINING OF ATHLETES IN THE DISCIPLINE OF SPORTS TOURISM "DISTANCE- HIKING"}

\section{E. Veber}

Summary: This article reveals the definition of sports tourism discipline "distance- hiking.» In the course of the study, the current educational programs of the sports tourism are reviewed, common features are identified and dynamic changes are identified that contribute to the development of this sport in a modern, dynamically developing society. The article also highlights the main sections of the training of athletes.

Keywords: sports tourism, training programs, stages of development of athletes, training process, development of competencies, "distance hiking".

\author{
Вебер Эльвина Павловна \\ Аспирант, Сургутский педагогический университет \\ Trainer_2012@mail.ru
}

Аннотация: В данной статье раскрывается определение спортивного туризма дисциплины «дистанция-пешеходная». В ходе осуществляемого исследования рассмотрены имеющиеся в настоящее время программы образовательной области спортивного туризма, выявлены общие черты и определены динамические изменения, способствующие развитию данного вида спорта в современном динамично развивающемся обществе. Также в статье отмечены основные разделы подготовки спортсменов.

Ключевые слова: спортивный туризм, учебно-тренировочные программы, этапы развития спортсменов, тренировочный процесс, развитие компетенций, «дистанция-пешеходная».

\section{Введение}

$\mathrm{B}$ настоящее время дисциплина «Дистанция» в спортивном туризме получила стремительное развитие. Данный рост можно наглядно увидеть через анализ прироста общего количества занимающихся в последние годы. Сравнивая количество занимающихся в иных группах спортивного туризма. По представленным аналитическим данным в период с 2013 г. по 2019 г. прирост составил $24 \%$ к первоначальному показателю.

Рассмотрим особенности спортивного туризма дисциплины «Дистанция», как вид спорта, представляет собой индивидуальное или командное прохождение дистанции по пересеченной местности с выполнением заданий (технических этапов) по преодолению естественных или искусственных препятствий который находится между линиями старта и финиша и оценивается при помощи комплекса судейского оборудования. С включением спортивного туризма, как отдельного вида спорта в ЕВСК сложность дистанции для соревнований возросла настолько, что без целенаправленной круглогодичной подготовки невозможно не только достигнуть высоких результатов, но даже само прохождение дистанции [4].

На основании того, что группа дисциплин «Дистан- ция» получила свое официальное оформление в 2008 г., исследований спортивной подготовки туристов в настоящее время немного, что сказывается на методическом обеспечении и развитии технологий обучения данной группы дисциплин. Имеющийся пробел играет значительную роль в необходимости более детального исследования и совершенствования процесса анализа теории и методики спортивной подготовки спортсменов.

Статистические данные показывают, что в период с 2013 года по настоящее время количество спортсменов, которые занимаются в группе дисциплин «Дистанцияпешеходная» значительно увеличилось. Проведенный анализ протоколов результатов массовых соревнований по спортивному туризму, которые были проведены в различных субъектах Российской Федерации, а также в соревнованиях федерального уровня, показывает, что численность спортсменов уровня «юниор» увеличилась достаточно существенно. При исследовании трех видов соревнований «Юный турист России», массовые соревнования по спортивному туризму «Гонка четырех» и Московский фестиваль детско-юношеского туризма - Открытый кубок города Москвы, указывают на то, что численность участников соревновательного процесса значительно увеличилась. Значимым аспектом развития группы спортивной дисциплины «Дистанция-пешеходная» становится зрелищный характер соревновательно- 
го процесса, который предполагает приобщение большого количества представителей молодого поколения к активному образу жизни и спорту больших достижений.

Специфические особенности спортивного туризма через призму дисциплины «Дистанция-пешеходная» связаны с большим количеством наблюдателей, представителей судейских бригад, а также общей зрелищности этапов каждого проводимого соревновательного мероприятия [2].

Отсутствие необходимой информации по методическому обеспечению развития тренировочного процесса в группе дисциплин «Дистанция - пешеходная» не позволяет видеть перспективы развития вида спорта и соответствующим образом строить подготовку спортсменов-туристов. Так, в настоящее время нет однозначного понимания о необходимых объемах тренировочной нагрузки, соотношении различных видов подготовки в тренировочном процессе, ведущих физических качествах в структуре подготовленности спортсменов-туристов.

\section{Шель исследования}

Цель исследования - изучение программно-методического обеспечения, в группе дисциплин спортивного туризма основываясь на специализацию «Дистанция-пешеходная».

\section{Захачи исследования}

Проанализировать основные программы по спортивному туризму.

Изучить структуру содержания программ.

Определить ведущие разделы в содержании программ.

\section{Методы исследования}

В работе использованы анализ научно-методической литературы, анализ протоколов результатов соревнований, анализ и обобщение данных по программно-методическому обеспечению подготовки групп начальной подготовки спортсменов в дисциплине спортивного туризма «Дистанция-пешеходная», за период 2008 г. - 2020 r.

\section{Обсужкение результатов}

При осуществлении подготовки спортсменов в указанной группе необходимо применение системного, комплексного подхода, а также развитие многолетних традиций учебно-тренировочной деятельности как процесса, который ориентирован на получение высокой результативности основных показателей. Реализация на практике структурных элементов программы подготовки спортивного туризма дисциплине способствует получению спортивных разрядов, званий и выполнению нормативов согласно показателям Единой всероссийской спортивной классификации (ЕВСК).

Инновационная направленность используемого программного обеспечения связана с возможностью построения непрерывного и комплексного учебно-тренировочного процесса в области развития и совершенствования показателей спортсменов - туристов [2].

Анализ содержательной части программно-методического обеспечения в области спортивного туризма позволяет обратить внимание на развитие трех направлений: основы туризма, спортивный туризм групп дисциплин - «Дистанции» и спортивное ориентирование. Они представляют собой значительную часть осуществления соревновательной деятельности через прохождение определенной спортивной дистанции.

В практике реализации программного обеспечения в спортивном туризме в настоящее время рекомендовано использовать современные методики по осуществлению физической подготовки, которые представляют собой комплексы упражнений, необходимые для комплексного развития и совершенствования специальной выносливости спортсменов [2]

На основании исследования программного материала, необходимо отметить, что осуществляемая подготовка к профессиональному самоопределению обучающихся должна быть обусловлена большим разнообразием используемых видов деятельности, которое изначально закладывается в программе «Спортивный туризм».

Рассмотрим варианты программ, которые адаптированы под конкретные образовательные спортивные организации, занимающиеся развитием спортсменов занимающихся группой дисциплины в спортивном туризме «Дистанция-пешеходная».

Программа спортивной подготовки для СДЮШОР включает в себя следующие составные элементы: нормативную часть программы, методическую часть учебной программы, календарно - тематическое планирование, этапы осуществления спортивной подготовки, осуществление врачебного и педагогического контроля, основы теоретической подготовки, особенности осуществления воспитательной работы и психологической подготовки, анализ восстановительных средств и комплекса осуществляемых мероприятий.

Отметим плюсы и минусы реализации данной программы:

- положительным фактором является системати- 
зация ПВК (профессионально важных качеств) спортсменов - туристов, определение элементов учебно-тренировочного плана по дисциплине «Дистанция-пешеходная»;

- можно обратить внимание на то, что в данной программе не расписаны особенности, которые связаны с практикой подготовки спортсменов по уровням (начальный, средний, выше среднего и высокий);

- не указаны те профессиональные спортивные компетенции, которые необходимо вырабатывать при подготовке к спортивным соревнованиям дисциплины «Дистанция-пешеходная».

Рассмотрим индивидуальную рабочую программу для одаренных детей, составленную Ивановой Т.В., по дисциплине «Спортивный туризм дисциплина - Дистанция». Создание данной программы обусловлено тем, что имеющиеся типовые программы для объединений туристско-краеведческого направления рассчитаны на работу группами детей численностью 10-12 человек. Результат выступления команды зависит во многом от капитана. Подготовка ребенка к работе в качестве капитана - один из важнейших этапов роста спортивного мастерства.

Отметим положительные и отрицательные черты данной рабочей программы по спортивной дисциплине «Дистанция»:

- в данной программе подробно расписан учебно - тематический план по данной дисциплине (цель этапа, организация быта в полевых условиях, медицинский контроль и самоконтроль, осуществление технической и тактической подготовки спортсменов, планируемые результаты);

- данные составляющие элементы плана расписываются непосредственно к каждому из этапов осуществляемой деятельности;

- в программе указываются основные формы контроля, обеспечение реализации программы, предоставляются основные рекомендации для ее практической реализации;

- программа является не достаточно полной, в ней отсутствуют основные ЗУН (знания, умения и навыки для подготовки и развития спортсмена - туриста), не расписаны компетенции и их уровни по этапам подготовки, а также важно обратить внимание на то, что данная программа носит локальный характер;

- минусом является возраст занимающихся, программа рассчитана на 13 летний возраст, по регламенту с 8 лет уже дети могут участвовать в соревнованиях 1 класса дистанции, это говорит о том, что спортсменов нужно готовить к 8 годам.

Интерес вызывает также дополнительная общераз- вивающая программа «Многогранный вид туризма». В данной программе отмечено то, что Привлекательность занятий спортивным туризмом состоит также и в разнообразии его видов. Туризм - это вид деятельности, включающий в себя серьезную физическую подготовку в зале и на свежем воздухе, теоретические занятия, специальные тренировки, сборы, соревнования на маршрутах (походы) и на дистанциях. Данная программа не ограничивает вид туризма (пешеходный, горный, лыжный, водный), а занятия, особенно на местности, проходят в соответствии с сезоном года. Во время подготовки к походам и соревнованиям для всех учащихся в обязательном порядке проходят занятия по основам оказания первой доврачебной помощи. Подготовка к спортивным дистанциям включает работу на различных естественных препятствиях (реки, скалы, обрывы и др.) на местности и в спортивном зале (искусственные объекты) со специальным оборудованием, как в команде, в связках, так и лично. Основной отличительной особенностью программы является включение в ее содержание досуговой деятельности. Исходя из основного направления образовательной работы программа предполагает участие школьников в различных видах соревнований по спортивному туризму, поэтому она разработана с учетом требований новых нормативных документов по спортивному туризму:

- разрядные требования, группа дисциплин «Дистанция» (утверждены приказом Минспорттуризма России от 08 апреля 2009 г., № 194);

- регламенты проведения соревнований по дисциплинам «Дистанция - лыжная», «Дистанция - горная», «Дистанция - комбинированная» (Москва, 2009);

- правила по спортивному туризму (утверждены Росспортом 22.07.13).

- регламент проведения спортивных соревнований по спортивному туризму (Дистанция - пешеходная, Дистанция - пешеходная - связка, Дистанция -пешеходная - группа) (Москва, 2014);

- методические рекомендации по организации и проведению туристских походов с обучающимися (Москва, 2015). Отличительной особенностью занятий и тренировок по подготовке к соревнованиям на Дистанциях является то, что отдельно изучаются вопросы технико-тактической подготовки видов: личной, командной короткой и командной длинной дистанций.

Положительной составляющей данной программы является то, что:

- усложнение материала из года в год осуществляется концентрическим способом (происходит возврат к тем же темам, но с более широким и углубленным изучением), с учетом индивидуальных способностей детей (физических, творческих, морально-волевых); 
- цель программы представляет собой развитие физических и интеллектуальных способностей детей и подростков, воспитание морально-нравственных качеств гражданина России в процессе занятий спортивным туризмом.

\section{Выводы}

При организации процесса обучения по дисциплине «Дистанция-пешеходная» спортсмены - туристы получают представления о специфике данной спортивной дисциплины, примеряя на себя возможность практического применения знаний, умений и компетенций.

Одним из существенно значимых аспектов обучения по образовательной области «спортивный туризм» является осуществление диагностических процедур (контрольные тренировки, занятия ОФП, медосмотры спортсменов), развития личностных качеств и основных показателей.

Целью программы «спортивный туризм» является создание условий для организации многолетнего процесса подготовки спортсменов-туристов при создании условий выполнения ими основных норм для получения высоких спортивных показателей, последующего присвоения на основании результативности спортивных разрядов и званий спортивной дисциплины - дистанция (вид спорта - туризм спортивный) Единой всероссийской спортивной классификации.

Программный материал образовательной области «спортивный туризм» имеет возможность для своего объединения в систему многолетней спортивной подготовки, что создает условия для получения качественного решения задач осуществления спортивной подготовки и результативности основных показателей при реализации комплекса процедур и действий на каждом этапе подготовки.

Необходимо отметить, что на этапе начальной подготовки спортсменов- туристов, должны быть выполнены следующие задачи осуществляемой деятельности:

- формирование устойчивого интереса к занятиям спортом через практику применения основных технологических, тактических и стратегических приемов;

- формирование достаточно широкого круга двигательных умений и навыков спортсменов - туристов;

- необходимость осуществления воспитательного процесса при развитии специальных способностей для максимально успешного овладения навыками спортивного туризма при практическом использовании основных особенностей вида дисциплин группы «Дистанция-пешеходная»;
- возможность для обучения основам техники с учётом особенностей вида дисциплин группы «Дистанция-пешеходная»;

- всестороннее гармоничное развитие физических качеств спортсменов - туристов;

- возможность для развития основных навыков, а также укрепление здоровья спортсменов;

- предоставление условий для осуществления выполнения основных норм на присвоение юношеских спортивных разрядов Единой всероссийской спортивной классификации [2].

В методических трудах А.М. Ларионова выделено большое количество разнообразных организационных форм организации педагогического процесса при осуществлении организации процесса обучения по дисциплине «Дистанция-пешеходная»: может быть организовано использование учебных, тренировочных и контрольных форм осуществляемой деятельности.

При этом должно быть организовано использование следующих форм занятий: теоретическое занятие, практическое занятие и спортивное соревнование. В качестве основных задач, которые необходимы для использования теоретических занятий выступает процесс ознакомления спортсменов с целью выполняемой ими деятельности, ее структурой.

Большую важность также имеет:

- организация процесса освоения знаний, умений, навыков;

- формирование у спортсменов представлений освоения знаний, умений, навыков;

- формирование представлений о целостном эффекте деятельности, а также об условиях, правилах, методах совершенствования при использовании различных форм занятий.

Практические, или тренировочные, занятия должны быть нацелены на решение задач формирования знаний, умений посредством освоения отдельных компонентов и осуществления их взаимосвязи в процессе деятельности, а также развития и совершенствования качеств и функционирования способностей всей системы, общей функциональной подготовленности и готовности к конкретной туристско-спортивной деятельности.

В ходе анализа программного обеспечения образовательной области «спортивный туризм» можно отметить преемственность этапов развития основных ЗУН и компетенций спортсмена - туриста. При этом применение осуществляемся по принципу от простого к сложному, при единстве используемых подходов, актуализации применения на практике тактики и стратегии развития указанной спортивной дисциплины [3]. 
Результатом осуществляемой педагогической работы тренерского состава спортивных школ и спортивных клубов должна становиться выстроенная единая педагогическая система, обеспечивающая преемственность задач, средств, методов, организационных форм подготовки всех возрастных групп при практике освоения дисциплины «Дистанция-пешеходная». Основным критерием эффективности многолетней подготовки при этом является получаемый наивысший спортивный результат, достигнутый в оптимальных возрастных границах.

Программа по образовательной области «спортивный туризм» при освоении спортивной дисциплины «Дистанция-пешеходная» включает в себя комплексные занятия, теоретические и практические занятия по технике туризма, тренировки по общефизической и специальной физической подготовке (ОФП и СФП) [4].

К общеразвивающим упражнениям при этом необходимо отнести различного рода упражнения, которые направлены на развитие и воспитание основных физических качеств, укрепление мышц и связок, совершенствование координационных способностей организма.

Занятия по ОФП в комплексе реализации программного обеспечения образовательной области «спортивный туризм» при освоении основных элементов спортивной дисциплины «Дистанция-пешеходная» должны быть направлены на комплексную тренировку всех групп мышц с обязательным включением кроссовой подготовки. Специальная физическая подготовка при этом должна быть обращена на развитие специфических физических качеств, необходимых в спортивном туризме: специальной выносливости, скоростной выносливости, силовой выносливости, силы, ловкости и быстроты. Теоретические занятия имеют определенную целевую направленность: вырабатывать у занимающихся умение использовать полученные знания на практике в условиях тренировочных занятий.

Занятия в рамках применения программного обеспечения образовательной области «спортивный туризм» при освоении основных элементов спортивной дисциплины «Дистанция-пешеходная» должны проводиться с использованием различных форм организации учебной деятельности (групповая, массовая, индивидуальная). Разные типы и формы занятий создают условия для развития познавательной активности, повышения интереса детей к обучению [3].

Рекомендуемые типы занятий: изучение новой информации, занятия по формированию новых умений, обобщение и систематизация изученного, практическое применение знаний, умений (закрепление), комбинированные занятия, контрольно- проверочные занятия, тестирование. Рекомендуемые формы занятий при ос- воении основных элементов спортивной дисциплины «Дистанция-пешеходная»: учебные занятия в кабинете и учебно-тренировочные занятия на местности, занятия по ОФП и СФП в спортивном зале и на местности.

Согласно концепции подготовки в спортивном туризме дисциплина «Дистанция-пешеходная», которая была предложена для практической реализации в спортивных школах олимпийского резерва А.С. Подгорной, годичный цикл тренировки спортсменов туристов состоит из трех периодов: подготовительного, соревновательного и переходного [3].

При этом подготовительный период включает в себя: 2 этапа - обще-подготовительный и специально-подготовительный; 4 мезоцикла - втягивающий, базовый развивающий, базовый специально-подготовительный и предсоревновательный; 10-12 микроциклов. Соревновательный период включает в себя два соревновательных этапа и один промежуточный.

Переходный период должен включать в себя 2 основных этапа (переходный активный и переходный пассивный - отдых). В качестве основной, которая носить большую содержательность, стороны концепции периодизации спортивной тренировки является методология построения тренировочного процесса в микро, мезо и макроциклах.

Она должна быть выражена в определении объёмов различных видов подготовки спортсменов - туристов (физической, технической, тактической и соревновательной) и их соотношении, в динамике осуществляемых тренировочных и соревновательных нагрузок различного характера и направленности, в направленности, в последовательности и имеющейся взаимосвязи отдельных звеньев тренировочного процесса, в динамике средств и используемых методов [6].

На основании использования концепции достаточно существенная часть объёма суммарной (тренировочной и соревновательной) нагрузки должна быть отведена на физическую подготовку (50-80 \%).

Организация процесса подготовки спортсменов - туристов в искусственных условиях должны быть небольшие по объему, однако, должны обладать достаточной интенсивностью, а также должны иметь направленность на то, чтобы повышать силовые, скоростно-силовые качества и специальную выносливость в условиях организации присутствия адекватной соревновательной деятельности, которая характеризуется применением круговой формы организации тренировки.

В условиях осуществления тренировочного процесса на естественном рельефе приоритет должен быть 
отведен технико-тактической и соревновательной подготовке.

Специальная физическая подготовка должна быть осуществлена в единстве с технико-тактической, при наличии общего акцента на развитие скоростных, скоростно-силовых качеств и скоростной выносливости.

В данной связи на этапе технико-тактической подготовки заметно может быть изменена динамика нагрузок. Небольшое снижение аэробной и значительное увеличение анаэробно-лактатной нагрузки является характерным для этапа специальной подготовки.

Большое количество различных специалистов и тренеров придают существенную значимость организации и непосредственному осуществлению соревнователь- ной подготовки в виде учебно-тренировочных, контрольных внутригрупповых соревнований, в которых помимо решения задач тактической подготовки осуществляется повышение специальной физической подготовки.

Таким образом, используемая программа образовательной области «спортивный туризм» предназначена для тренеров-преподавателей и педагогов дополнительного образования спортивных секций и объединений по спортивному туризму учреждений дополнительного образования.

Различные климатические условия и наличие материальной базы могут служить основанием для корректировки рекомендуемой программы.

\section{ЛИТЕРАТУРА}

1. Егорова, Г.Н. Программа комплексной подготовки по спортивному туризму [Текст] / Г.Н. Егорова. - Новокузнецк: ДЮЦ «Орион», 2018. - 27 с.

2. Кропочев, В.А. Программа комплексной туристской подготовки ДЮЦ «Орион» Центрального района г. Новокузнецка. [Текст] / В.А. Кропочев. - Новокузнецк, ДЮЦ «Орион», 2015 г. - 32 с.

3. Маслов, А.Г. Программа для системы дополнительного образования детей «Юные инструктора туризма» [Текст] / А.Г. Маслов. - М. : ЦДЮТур, 2018. - 55с.

4. Минхаиров, Ф.Ф. Турист на дистанции. В помощь начинающему тренеру [Текст] / Ф.Ф. Минхаиров. - Казань: РИЦ Школа, 2014 - $148 c$.

5. Образовательная программа «Спортивный туризм. Дисциплина - дистанция пешеходная»//Федоров А.Е.//Согласовано с Методическим советом ГБОУ «СПб - ГДТЮ», 2013 г.

6. Примерные требования к программам дополнительного образования детей. [Текст] / Приложение к письму Минобрнауки России // Дополнительное образование. - 2007. - №3. - С. 5-7.

7. Подласый, И.П. Педагогика. Новый курс: Книга 1, 2 [Текст] / И.П. Подласый. - Изд-во: ВЛАДОС, 2016. - 576 с.

8. «Содержание, структура и оформление программ дополнительного образования детей» [Текст] / Приложение к письму Минобрнауки России от 11.12 .06 №06-1844 «0 примерных требованиях к программам дополнительного образования детей» // Нормативные документы образовательного учреждения. - 2008. - №3. - С.39-42.

9. Федерация спортивного туризма России Санкт-Петербурга - сайт rfstspb.ru

10. Федерация спортивного туризма России Санкт-Петербурга / В контакте - https://vk.com/club106554 